\title{
DEVELOPMENT OF A NEW GENERATION OF FILAMENT WOUND COMPOSITE PRESSURE CYLINDERS
}

\author{
J. C. Velosa ${ }^{1}$, J. P. Nunes ${ }^{1}$, P. J. Antunes ${ }^{1}$, J. F. Silva ${ }^{2}$, A. T. Marques ${ }^{3}$ \\ ${ }^{1}$ Polymer Engineering Department, Minho University, Campus de Azurém, 4800-058 Guimarães, Portugal \\ ${ }^{2}$ Department of Mechanical Engineering, ISEP, 4200-072 Porto, Portugal \\ ${ }^{3}$ DEMEGI-INEGI-FEUP, Universidade do Porto, 4465-591 Leça do Balio, Portugal \\ ${ }^{1}$ Email: jcvelosa@dep.uminho.pt
}

\begin{abstract}
A new generation of composite pressure vessels for large scale market applications has been studied in this work. The vessels consist on a thermoplastic liner wrapped with a filament winding glass fibre reinforced polymer matrix structure. A high density polyethylene (HDPE) was selected as liner and a thermosetting resin was used as matrices in the glass reinforced filament wound laminate.

The Abaqus 6.5.1 FEM package were used to predict the mechanical behaviour of pressure vessels with capacity of approximately of $0,068 \mathrm{~m}^{3}(68 \mathrm{l})$ for a $0.6 \mathrm{MPa}(6 \mathrm{bar})$ pressure service condition according to the requirements of the prEN 13923 standard, namely, the minimum internal burst pressure. The Tsai-Wu and Von Mises criteria were used to predict composite laminate and thermoplastic liner failures, respectively, considering the elasto-plastic behaviour of the HDPE liner and the laminae properties deducted from micromechanical models for composite laminates.
\end{abstract}

Finally, prototype pressure vessels were produced in the defined conditions to be submitted to pressure tests. The comparison between the FEM simulations and experimental results are discussed in the present paper.

\section{INTRODUCTION}

Traditional materials, such as, steel, are successfully being replaced by polymer matrix composites materials in the construction of pressure cylinders for many common applications. The use of polymer composites allows minimising the weight, improving the aesthetic and also increasing the pressure vessel mechanical, impact and corrosion behaviour [1]. These are important attributes in many present and future industrial and non-industrial large scale applications, such as, for example, liquid filters and accumulators, hydrogen cell storage vessels, oxygen bottles, etc.

Multi-axial filament winding is the more adequate processing technology to produce composite vessels for medium to high internal pressures at serial industrial level $[2,3]$. Such technology allows processing simultaneously the vessel cylinder and domes and use non-geodesic optimised fibre patterns in the composite laminate layers that permit withstand the higher mechanical efforts involved with lower vessel-wall thicknesses.

This work is part of a larger study concerning the development of a new generation of filament wound composite vessels to be applied on the storage of industrial uncompressed fluids under pressure. The present paper only covers an initial part of the work that concerns the manufacture and simulation of the behaviour of pressure vessels made from fibre reinforced thermosetting matrix composites. Later, pressure vessels made from fibre reinforced thermoplastic matrix composites will be also studied in the project.

Ciência e Tecnologia dos Materiais, Vol.19, $n^{\circ} 1 / 2,2007$ 
A vessel consisting in a thermoplastic liner wrapped with a filament winding glass fibre reinforced thermosetting resin structure has been studied. The finite element analysis (FEM) was used to predict the pressure vessel mechanical behaviour according to the requirements of the prEN 13923 standard, namely, the minimum internal burst pressure.

\section{EXPERIMENTAL}

\subsection{Characteristics of the pressure vessel and raw materials}

A pressure vessel, with the dimensions shown in Figure 1, having the capacity and internal diameter of $0.068 \mathrm{~m}^{3}$ and $205 \mathrm{~mm}$, respectively, was chosen to be studied in this work.

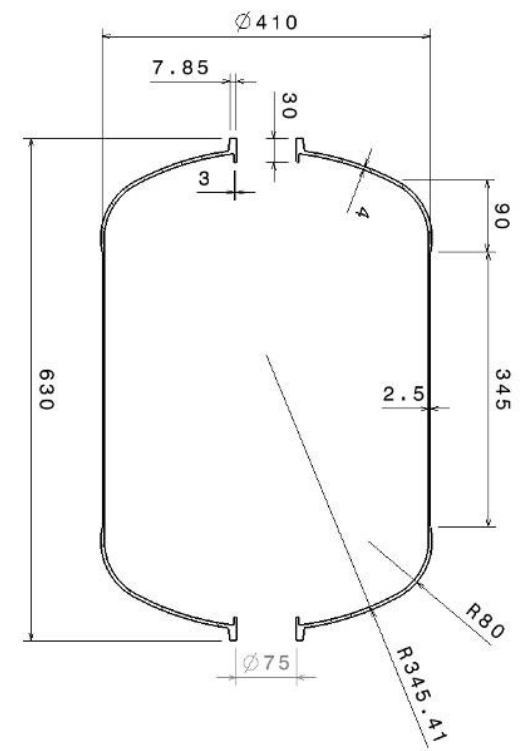

Fig. 1. Dimensions of the pressure vessel under studied

A thermosetting orthophthalic unsaturated polyester resin matrix reinforced with a weight percentage of $70 \%$ of 2400 Tex type E continuous glass fibres was selected to be used in the pressure vessel structural wall laminate. Table 1 summarises the mechanical properties of structural wall glass reinforced unsaturated polyester (GF/UP) laminae. The values under the column "Calculated Values" were predicted from the manufacturer data sheets using well-know micromechanical models forcomposite materials [4-7].

A high density polyethylene (HDPE), Rigidex ${ }^{\circledR}$ HD3840UR from INEOS, has been selected to produce the thermoplastic liner by rotational moulding. Table 2 shows the main properties of this HDPE presented in the manufacturer data sheets.

Figure 2 depicts the HDPE liner produced by rotational moulding in the Portuguese company ROTOPORT that is being used in the present work. For testing and evaluate their performance, two different types of threads were used in end-domes liner fittings: a HDPE thread directly manufactured in the liner during the rotational moulding process and a metallic thread insert that was incorporated in the HDPE liner wall. 
Table 1 - Properties of the GF/UP laminae

\begin{tabular}{l|c|c|c}
\hline \multicolumn{1}{c|}{ Property } & Unit & Data Sheet values & Calculated Values \\
\hline Longitudinal Strength & $\mathrm{MPa}$ & 800 & - \\
Longitudinal Modulus & $\mathrm{GPa}$ & 40 & - \\
Transversal Strength & $\mathrm{MPa}$ & - & 40 \\
Transversal Modulus & $\mathrm{GPa}$ & - & 10 \\
Shear Strength & $\mathrm{MPa}$ & - & 35 \\
Shear Modulus & $\mathrm{GPa}$ & - & 0.5 \\
Poisson's Ratio & - & - & 0.35 \\
Density & $\mathrm{g} / \mathrm{cm}^{3}$ & - & 1.9 \\
Glass mass content & $\%$ & 70 & - \\
Glass volume content & $\%$ & - & 52 \\
\hline
\end{tabular}

Table 2 - Properties of the HDPE liner

\begin{tabular}{l|c|c|}
\hline \multicolumn{1}{c|}{ Property } & Unit & Value \\
\hline Tensile modulus & $\mathrm{MPa}$ & 650 \\
Yield stress & $\mathrm{MPa}$ & 19 \\
Yield strain & $\%$ & 11 \\
Elongation at break & $\%$ & $>1000$ \\
Density & $\mathrm{g} / \mathrm{cm}^{3}$ & 0.94 \\
\hline
\end{tabular}

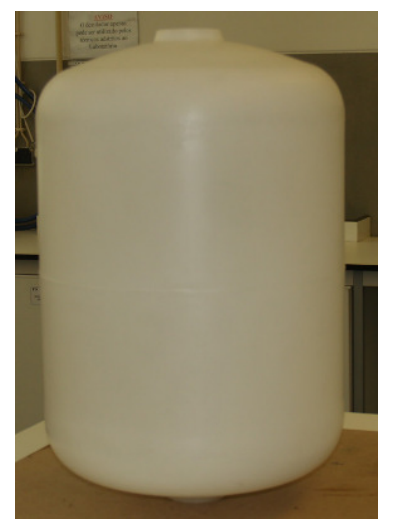

Fig. 2. Rotational moulding HDPE liner 


\subsection{FEM analysis}

Abaqus 6.5 FEM packages [8] were used to predict the mechanical behaviour of the pressure vessel cylinder by finite element analysis. Non-linear analyses were used in the mechanical behaviour simulations, first of the HDPE liner alone and after of the overall composite pressure vessel consisting in the HDPE liner wrapped by GF/UP laminate. The properties previously presented in Tables 1 and 2 for the GF/UP lamina and HDPE liner, respectively, were used in the simulations. The HDPE liner was considered to have elasto-plastic behaviour and the Von-Mises and Tsai-Wu criteria were used to predict the failure in the HDPE liner and GF/UP laminate, respectively.

Fibre orientation, thickness distribution, stacking sequence and number of layers were the parameters used to describe the laminate composite structure using shell composite linear elements. Figure 3 shows the ply stacking sequence and the material orientation angles used in the cylindrical vessel zone FEM simulations.

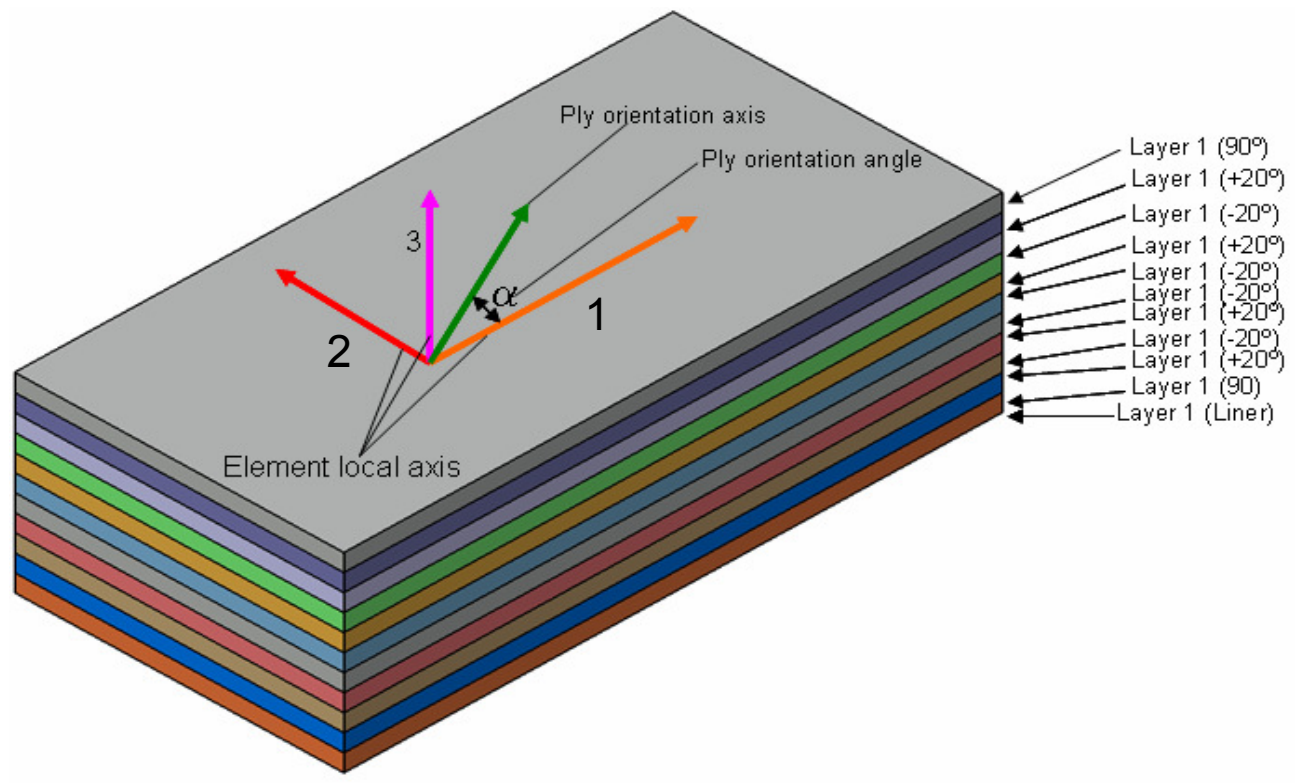

Fig. 3- Ply stacking sequence and material orientations angles in cylinder

Simpson's integration rule (three points though the thickness) was used to calculate the cross-sectional behaviour of the shell. Reduced integration formulation was applied in the stiffness matrix shear components and the full integration in other matrix terms. The elements were stabilized for spurious modes, enabling a correct discrete spatial description.

As Figure 4 shows, the variation of the thickness in different zones along the vessel was taken into account in the FEM model. 

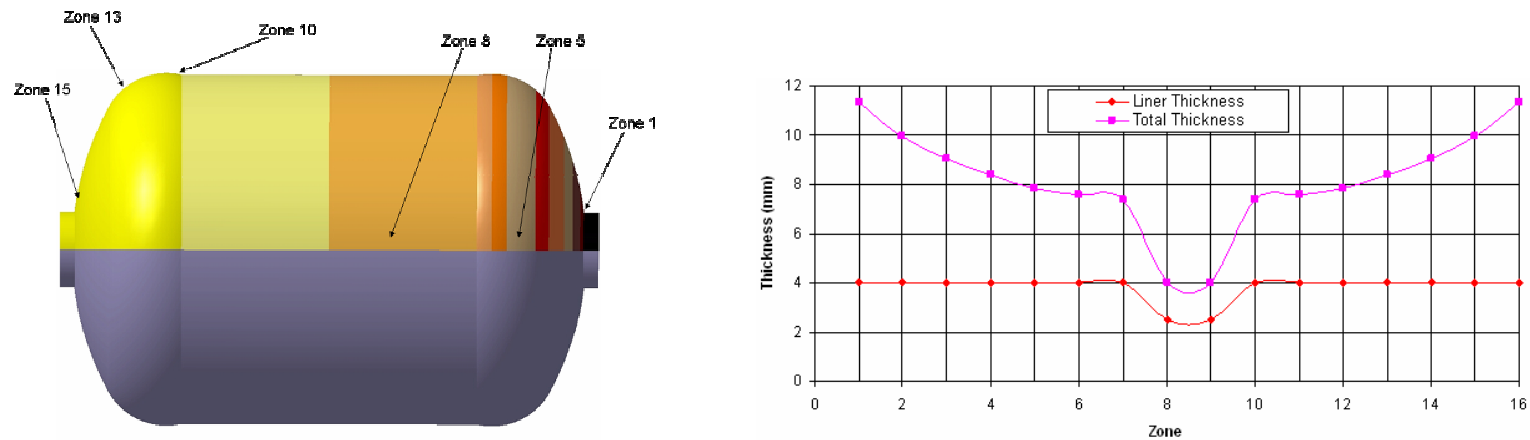

Fig. 4 - Variation of the thickness along the composite vessel

As it may be seen in Figure 4, the composite thickness varies along the vessel length reaching maximum values near the end-dome fittings due to the filament winding stacking process.

\subsection{Results and discussion}

To predict the HDPE liner burst pressure, it was submitted alone to a constant internal pressure increase in the FEA model. The Von Mises stresses and strains fields obtained from the simulations conducted in the HDPE liner are shown in Figures 5 and 6.

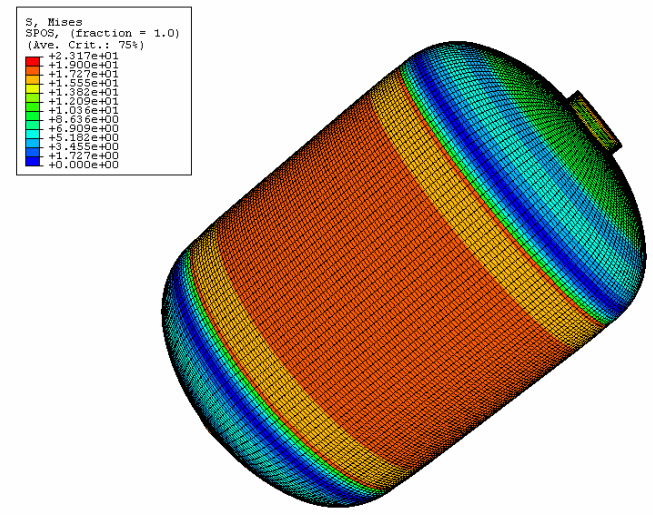

a) at the pressure of $2.4 \mathrm{bar}$

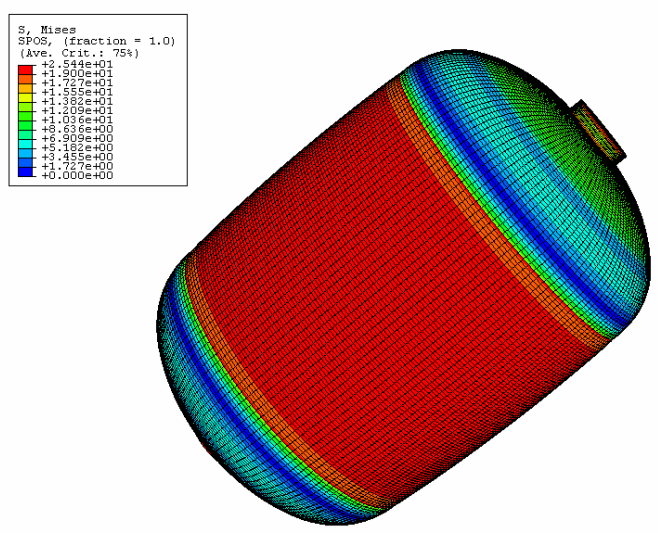

b) at the pressure of 2.64 bar

Fig. 5 - Von Mises field stresses determined in the HDPE liner 


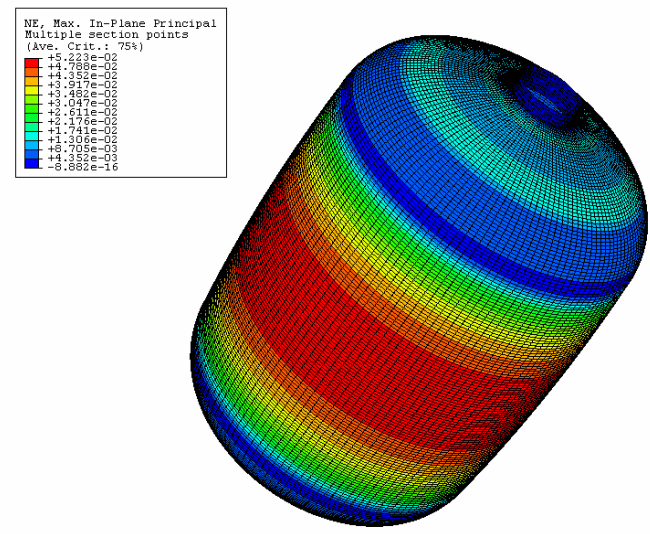

a) at the pressure of $2.4 \mathrm{bar}$

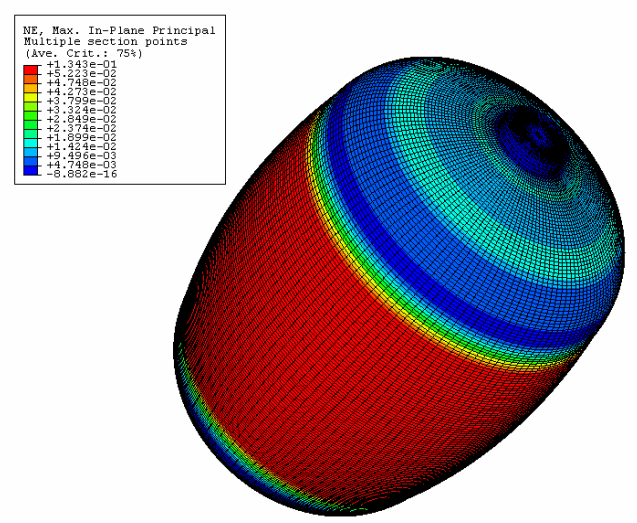

b) at the pressure of 2.64 bar

Fig. 1 - Nominal strains fields determined in the HDPE liner $(\mathrm{P}=2.64$ bar $)$

As it may be seen in above figures, the results determined allowed predicting that HDPE liner burst occurred at internal pressures between 2.4 and 2.6 (bar).

FEM simulations were then conducted on the overall composite pressure vessel considering the elasto-plastic and elastic behaviours in the HDPE liner and GF/UP laminate in the Abaqus 6.5.1 software package. The objective was to find a GF/UP composite laminate able to withstand a maximum internal initial burst pressure of 18 bar. According to the requirements of the prEN 13923 standard, for such burst pressure the vessel could be commercialised to withstand a standard 6 bar service pressure.

To regularise the HDPE liner surface and obtain better finishing in the outside vessel surface, it was decided to use circumferential $\left(90^{\circ}\right)$ layers in the initial and final laminae of the GF/UP composite laminate. It was also chosen to built the remaining GF/UP laminate using cross-ply layers with fibres oriented at $\pm \alpha$. A deep research has been conducted in order to optimise the cross-ply angle between $20^{\circ}$ and $30^{\circ}$. Finally, a $\pm 20^{\circ}$ cross-ply laminate was chosen because the obtained results have shown that this kind of laminate was able to withstand higher internal pressures in the vessel.

Figure 7 shows the Tsai-Wu field stresses obtained in the exterior composite layer, with fibres oriented at $90^{\circ}$, when the composite vessel was submitted to a 24 bar internal pressure. As may be seen, this layer didn't show any trace of failure at this pressure. 


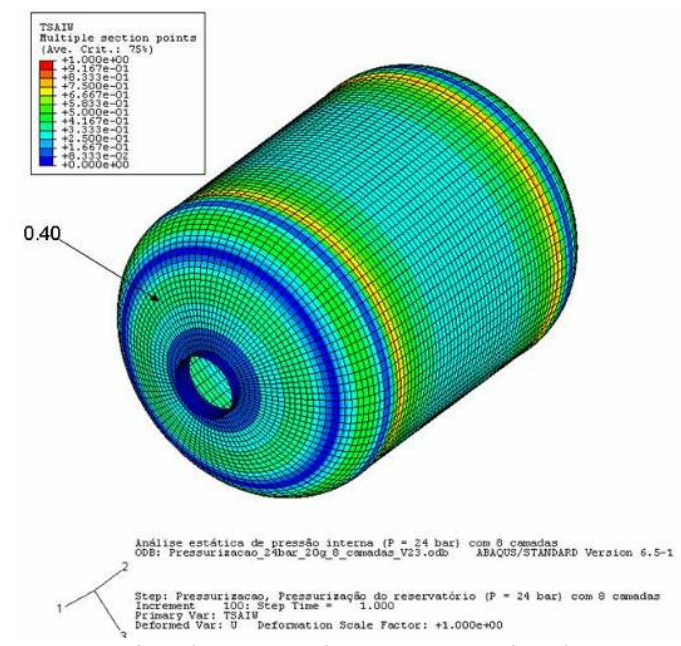

Fig. 7 - Tsai-Wu field stresses in the exterior composite layer at 24 bar internal pressure

However, as Figure 8 depicts, it was found that failure was near to occur in some cross-ply internal layers having fibres oriented at $\pm 20^{\circ}$ at lower vessel internal pressures. From this figure, it is possible to conclude that the FEM analysis predicted failure in the cross-ply layer number 15 of the GF/UP laminate at an internal pressure around 19 bar. Thus, the selected GF/UP composite laminate was considered appropriate to manufacture composite vessels for withstand the 6 bar standard service pressure.

A deep analysis allowed also to find that the high interlaminar shear stresses developed in the cross-ply layer number 15 were mainly responsible for the failure observed. Then, as previous works [9] have shown the FEM analysis using the Tsai-Wu failure criterion seems to give conservative estimations of composite vessels burst in these conditions, it is expected that subsequent pressure testing experiments to be made in prototype vessels demonstrate that they could enable to withstand higher service pressures ( 8 bar or 10 bar).

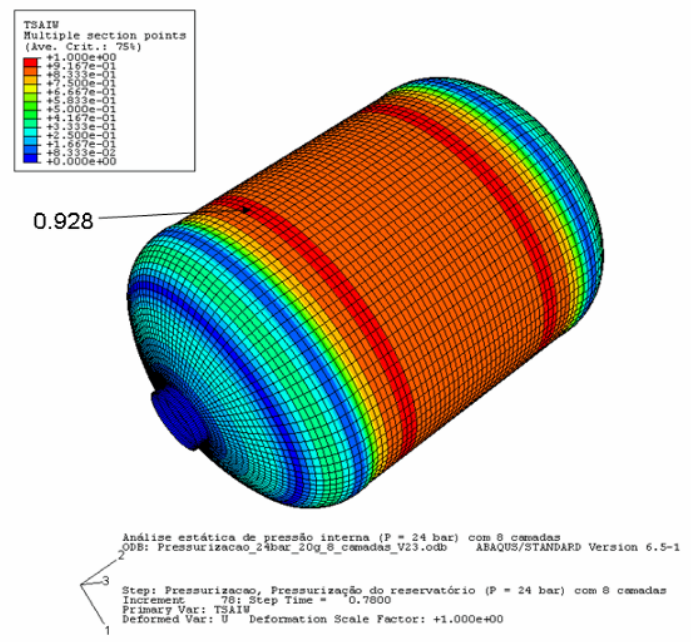

a) layer \#12 at pressure of 18.72 bar

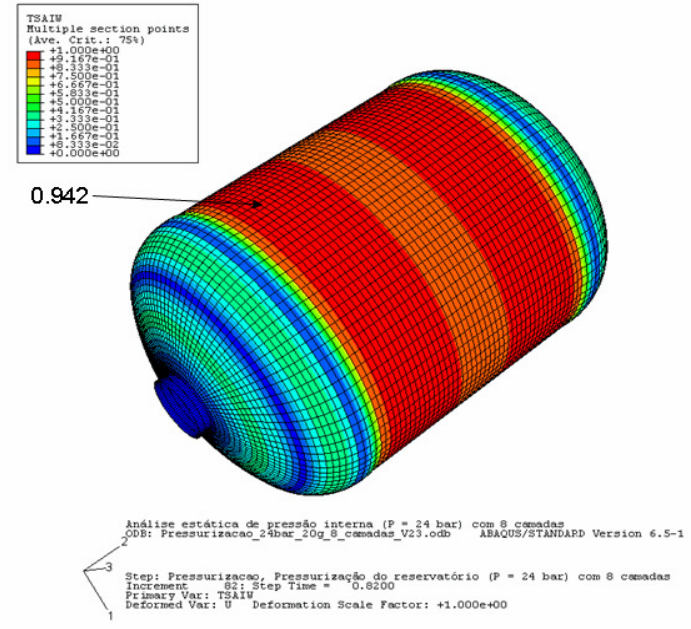

b) layer \#15 at pressure of 19.68 bar 
Fig. 8 - Tsai-Wu field stresses in the internal composite $\pm 20^{\circ}$ cross-ply layers

\subsection{Production of vessel prototypes}

Composite vessel prototypes to be submitted to pressure burst testing were produced using the HDPE liner and GF/UP laminate used in the FEM simulations in 6-axes PULTREX filament winding machine from INEGI. Figure 9 shows the initial tests made to deposit the $\pm 20^{\circ}$ cross-ply laminate layers on the HDPE liner.

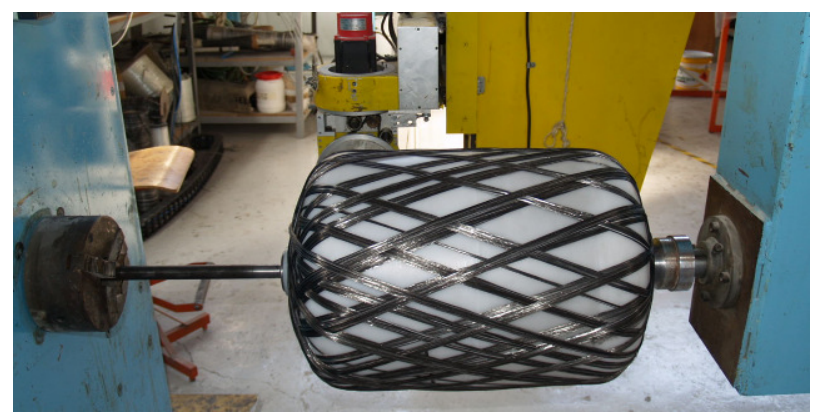

Fig. 9 - Initial tests to deposit the $\pm 20^{\circ}$ cross-ply laminate layers on the HDPE liner

As composite vessels are being submitted to pressure burst tests at this moment, more conclusive results from these tests will be discussed in the presentation of this paper.

\section{CONCLUSIONS}

This work shows that the FEM analyses could be a powerful tool to optimise composite pressure vessels lay-up. The FEM simulations made allowed concluding that the HDPE liner could withstand an internal pressure between 2.4 and 2.6 (bar). From the FEM simulations it was also possible to define the laminate to be used in the production of pressure composite vessels able to withstand the minimum standard service pressure of 6 bar, which according to the requirements of the EN 13923 standard enable to support burst pressure of 18 bar. Because the cross-ply laminate layers have shown to fail at this last pressure due to high interlaminar shear stresses, it is expected the prototype vessels that are being submitted to burst pressure tests enable to support higher burst pressures. In fact, previously works proven [9] that the interlaminar shear stresses are probably not main cause for overall failure of composite pressure vessels structural laminates.

\section{ACKNOWLEDGEMENTS}

Authors wish to thank the Portuguese Agency for the Development (ADI) for the financial support given to this work under the project "RESCOMPRE".

\section{REFERENCES}

1 Brandt, J., Drechsler, K., Richter, H., "The Use of High-Performance Thermoplastic Composites for Structural Aerospace Applications", 9th Int. Conference on Composite Materials (ICCM-9), Vol. 6, Madrid, Spain (1993) 143-150. 
2 Won-Man, C., Bang-Eop, L., Song-Hoe, K., Young-Shin, L. "Effects of Geometric and Material Nonlinearity on The Stresses of Various Pressure Vessel Dome Shapes” Computers \& Structures Vol. 55, No. 6 (1995) 1063-1075.

3 Kang, D.H., Kim, C.U., Kim, C.G. "The embedment of fiber Bragg grating sensors into filament wound pressure tanks considering multiplexing” NDT\&E Int., 39 (2006); 119-116.

4 Tsai, S.W., “Composites Design, Think Composites”, USA (1987).

5 Jones, R.M., "Mechanics of Composite Materials", International Student Edition, MacGraw-Hill Kogakusha Ltd, Tokyo (1975).

6 Saarela, O., "LAMDA-Laminate Design and Analysis", Helsinki University of Technology", Otaniemi, Finland (1992)

7 Nunes, J. P., Bernardo, C. A., Pouzada, A. S. e Edie, D. D., "Formation and Characterisation of Carbon/Polycarbonate Towpregs and Composites", Journal of Composite Materials, Vol. 31 (17), USA (1997) 1758-1777.

8 Abaqus Documentation, Version 6.5.1, Hibbitt, Karlsson \& Sorensen Inc.

9 Antunes, P. J., Dias, G. R., Nunes, J. P., van Hattum, F.W.J., Oliveira, T. "FEM Analysis of Thermoplastic Matrix Composite Gas Cylinders " Proceedings of the 15th Int. Conference on Composite Materials- ICCM 15, 27 June-1 July, Durban/South Africa, (2005).

Ciência e Tecnologia dos Materiais, Vol.19, $\mathrm{n}^{\circ} 1 / 2,2007$ 